\title{
Motivational cues as determiners of stimulus control in rats
}

\author{
DAVID C. ZUCKERMAN \\ Vassar College, Poughkeepsie, New York 12601
}

\begin{abstract}
Four rats were each trained to perform a light-intensity discrimination and a sound-intensity discrimination. For half of the subjects, light training sessions were preceded by food deprivation, and correct choices were reinforced with food. Sound training sessions, on the other hand, were preceded by water deprivation, and correct choices were reinforced with water. For the remaining subjects, light training sessions were associated with water deprivation, whereas sound sessions were associated with food deprivation. When the rats were tested in the presence of compounds of sound and light, choices tended to be controlled by light when testing was preceded by the deprivation condition associated with light discrimination task. Reliably fewer light-consistent choices were made under the other deprivation condition, though some preference for responding on the basis of light remained. Following extended training in the presence of all four combinations of light and sound stimuli, this preference was reduced somewhat. When additional testing sessions were preceded by combined food and water deprivation, the tendency to respond on the basis of either light or sound was shown to be related to both deprivation and reinforcement factors.
\end{abstract}

The behavior of any organism which has had extensive experience with its environment is under the potential control of stimuli lying along many different dimensions. Given that stimuli belonging to several of these are presented at once, which of these will control the organism's behavior? Heinemann, Chase, and Mandell (1968) have suggested that cues lying along some external dimension may function as discriminative stimuli which determine the extent to which behavior is controlled by cues along a second dimension. In their experiment, the value of a visual stimulus was found to modulate control by a set of auditory frequencies. Similar results are reported by Yarczower (1971) using the dimensions of line-tilt and wavelength.

The hypothesis advanced here is that control by external dimensions may also be determined by the internal cues arising from food or water deprivation.

\section{EXPERIMENT I}

Rats were deprived of either food or water on randomly alternating days. For half of the subjects, ocrrect choice responses on an auditory discrimination were reinforced with food following food deprivation while correct responses on a visual discrimination were reinforced with water following water deprivation. For the remaining subjects, food deprivation and reinforcement were associated with light, whereas water

This paper is based upon a thesis submitted in partial fulfillment of the requirements for the degree of Doctor of Philosophy in the Department of Psychology of Brown University. The author extends $h$ is thanks to Donald $S$. Blough, Russell M. Church, and Julius W. Kling for their guidance during the course of this study. This research was supported by Public Health Service Predoctoral Fellowship 2F01MH48169-03. Reprints may be obtained from the author at the Department of Psychology, Hood College, Frederick, Maryland 21701. deprivation and reinforcement were associated with sound. Choice behavior in the presence of sound-light compounds was then evaluated as a function of various deprivation and reinforcement conditions. While it has been previously demonstrated that overt spatial (Hull, 1933; Leeper, 1935; Wickens, Hall, \& Reid, 1949) and approach (Baker, 1950; Bliss et al., 1971: Heron, 1949) behaviors can be controlled by internal cues, the present study uses identical instrumental responses for each of the two discrimination tasks. Thus, any shift in control by light vs. sound must be attributed to a general tendency to respond on the basis of light or sound, rather than a shift in the likelihood of emitting a given overt response.

\section{Method}

Subjects. The subjects were four male albino Charles River rats of the CD strain which werc about six months old and experimentally naive at the beginning of the study.

Apparatus. A Plexiglas chamber measuring $21.6 \mathrm{~cm}$ high $\mathrm{x}$ $21.6 \mathrm{~cm}$ wide $\times 22.9 \mathrm{~cm}$ deep was used. One wall was painted flat black on the exterior and contained three $1.3-\mathrm{cm} \times 1.3-\mathrm{cm}$ response bars arranged horizontally $5.1 \mathrm{~cm}$ apart from each other and $6.4 \mathrm{~cm}$ above the wire mesh floor. The center bar was operated by a force of $.02 \mathrm{~N}$, where ${ }_{i s}$ side bars each required a force of $.05 \mathrm{~N}$. Two vertical aluminum dividers protruding $3.2 \mathrm{~cm}$ into the chamber separated the center bar from the two side bars. A translucent circular disc $3.2 \mathrm{~cm}$ in diam was mounted on the wall directly above the center bar and could be transilluminated by a GE 1822 bulb, Reinforcers were delivered into either an aluminum foodcup or an aluminum water dipper, both of which protruded $3.2 \mathrm{~cm}$ into the chamber underneath the center bar. The foodcup was located to the left of the water dipper, with the dividing line between them directly beneath the center bar. 45-mg Noyes pellets were delivered to the foodcup by a Gerbrands Model D-1 pellet dispenser, and water was presented by a Gerbrands dipper of the B/LH/D type. A 4-ohm speaker was mounted on the ceiling of the box directly above the center bar. The chamber was housed in an unfinished 
fiberboard compartment measuring $57.2 \mathrm{~cm}$ high $\times 61.0 \mathrm{~cm}$ wide $x 40.6 \mathrm{~cm}$ deep, which was equipped with a ventilating fan. $A$ $6-\mathrm{W} 125-\mathrm{V}$ bulb, mounted on the ceiling of the compartment, provided dim illumination throughout experimental sessions.

Two intensities of white noise were delivered to the subjects via the ceiling-mounted speaker. The loud stimulus (S1) was calibrated at $80 \mathrm{~dB}$ (re $.0002 \mathrm{dynes} / \mathrm{cm}^{2}$ ) by a General Radio sound level meter, type $1550-8$ (C scale), at the approximate position of the subject's head. The softer stimulus (S2) was set at $68 \mathrm{~dB}$, and the ambient noise level was $49 \mathrm{~dB}$. Light stimuli were delivered through the circular disc mounted above the center bar. Intensity was manipulated by passing the current source through a variable resistor. The bright list (L1) was calibrated at $2.5 \log \mathrm{fL}$, whereas the dim light (L2) was set at $1.3 \log \mathrm{fL}$ (SEI meter). All inputs to and outputs from the apparatus were connected with a LINC computer, which monitored experimental sessions and printed out daily results on a Teletype.

Pretraining. During the 7 -week interval prior to the beginning of training, subjects were exposed to randomly alternating food and water deprivation. For a period of $1 \mathrm{~h}$ each day, free access was given to both dry lab chow and tap water. At the end of this hour, either food or water was removed for a period of $23 \mathrm{~h}$, with the restriction that neither deprivation condition was used for more than 3 consecutive days. Subjects were magazine trained for both food and water and then shaped by the method of successive approximations to emit a two-chain response sequence consisting of a center-bar press followed by a side-bar press.

Procedure. Subjects were run for one session daily, Each subject was placed in the experimental chamber, and the beginning of a session was signaled by the illumination of the houselight. The subjects initiated individual trials by pressing the center bar. When Subjects 1 and 4 were food deprived, this response produced either the bright (L1) or dim (L2) light stimulus, according to a random schedule. Left-bar responses were reinforced with food in the presence of $\mathcal{L} 1$, whereas right-bar responses were reinforced in the presence of $L 2$. All other responses were extinguished. In the case of an incorrect response, the same stimulus was presented repeatedly until a correct choice was made. In addition, incorrect responses were followed by a blackout period of $5 \mathrm{sec}$ during which the houselight was extinguished. During this interval, a response to any of the three bars had the effect of resetting the blackout-interval timer.

When Subjects 1 and 4 were water deprived, center-bar responses produced either the loud (S1) or soft (S2) sound stimulus. Left-bar responses in the presence of $\mathrm{S} 1$ resulted in access to the water dipper for 3.0 sec. The consequences of an incorrect response were the same as those used in light sessions. For Subjects 2 and 3, sound stimuli were presented under food deprivation, whereas light stimuli were presented under water deprivation.

Following each session, subjects were returned to their home cages where they were deprived of both food and water for a period of $2 \mathrm{~h}$. Free access to both dry lab chow and tap water was then given for a period of $1 \mathrm{~h}$. At the end of this period, either food or water was removed for approximately $201 / 2 \mathrm{~h}$, with the restriction that no subject was either food or water deprived for more than 3 consecutive days.

At the outset of training, sessions were 70 corrected trials in length. A performance criterion of at least $90 \%$ correct choices, exclusive of correction trials, was established. When this criterion was met, the correction procedure (including the blackout penalty) was discontinued, and the probability of reinforcement for a correct choice was gradually reduced from 1.0 to 0.5 in steps of .125. At the same time, the number of trials defining a session was increased so as to maintain the number of reinforcements per session at about 70 . This procedure was completed after approximately 150 sessions for each subject.

Testing. Over the next approximately 30 sessions, four test sessions were inserted at random intervals into each subject's daily routine. Subjects were water deprived for Tests 1 and 3 and food deprived for Tests 2 and 4. Accordingly, only water reinforcement was available during Tests 1 and 3 , and only food reinforcement was available during Tests 2 and 4. During each test session, a center-bar response resulted in the presentation of a compound stimulus containing both a light and a sound component. Eacl compound was chosen at random without replacement from the block of four possible combinations of two lights and two sounds until all four had been presented. Test sessions were 128 trials in length.

Each compound stimulus was placed into one of two categories. Redundant compounds were those for which a subject would be expected to emit the same response, regardless of which component controlled choice behavior. Thus, a subject should respond to the left baI when presented with SILl because both of the elements SI and LI had been associated with left-bar choices during training. Similarly, right-bar responses are expected in the presence of S2L 2. Only correct choices in the presence of either of these compounds were reinforced.

Conflict compounds, on the other hand, contained elements which had been associated with different choices during training. A subject whose behavior was under the control of light stimuli would thus be expected to respond to the left bar in the presence of L1S2, while a subject under the control of sound would be expected to respond to the right bar. The reverse is true for the compound L2S1. Reinforcement was not available for any choices made in the presence of conflict compounds.

\section{RESULTS AND DISCUSSION}

During preliminary training, both a deprivation condition (hunger or thirst) and an external cue (the appearance of food or water) can become associated with a stimulus dimension; the results of tests following this training should reveal the extent to which these associations were formed. Thus, choices should be consistent with control by light for Subjects 1 and 4 under food deprivation and reinforcement and for Subjects 2 and 3 under water deprivation and reinforcement. When deprivation and reinforcement conditions are reversed, a shift towards control by sound would be expected. These predictions are supported by the data in Table 1a, which shows the proportions of choices consistent with control by light on conflict trials; a score approaching 1.0 represents strong control by light, whereas scores near zero indicate control by sound. While it is true that control by light vs. sound differs reliably across test conditions for all subjects, it will also be observed that control by sound is in no case very strong, with values in Table la hovering about .5 where they were expected to fall to zero. This cannot be interpreted as purely random choice behavior during these sessions, however, since Table $1 \mathrm{~b}$ shows nearly perfect performance for all subjects in the presence of redundant compounds, where both components direct the same choice. A more plausible explanation is that the particular light stimuli used were simply more salient, or noticeable, than the sound stimuli, resulting in disruption of performance on the sound task. It would be expected that any stimulus preferences due to saliency could be reduced through extended differential 
training in the presence of both stimulus components, and one of the aims of the second experiment was to test this prediction.

\section{EXPERIMENT II}

The results of the preliminary study show that either deprivation condition, reinforcement, or both can control the tendency to respond on the basis of light vs. sound. Since the hypothesis under investigation concerns control by deprivation state alone, these two factors must now be manipulated independently. This was the major purpose of the second study.

\section{Method}

Subjects and apparatus. The subjects and apparatus were the same as those used in the first study.

Procedure. Each subject was run daily in the presence of all four combinations of two lights and two sounds. When Subjects 1 and 4 were food deprived and Subjects 2 and 3 were water deprived, all correct choices based upon the light component were reinforced regardless of the sound component. Thus, left-bar responses were reinforced in the presence of L1SI and L1S2, whereas right-bar responses were correct for L2S1 and L2S2. Similarly, reinforcement for responding on the basis of sound stimuli was available to Subjects 1 and 4 under water deprivation and Subjects 2 and 3 under food deprivation. Under this condition, left-bar responses were correct for L1S2 and L2S2. Sessions preceded by either food or water deprivation alone will be referred to as training sessions.

After the performance of each subject on the sound discrimination appeared to have stabilized at an improved level of accuracy over that observed in Experiment $I$, eight sessions preceded by $201 / 2 \mathrm{~h}$ deprivation of both food and water were inserted at random intervals into the series of training sessions described above. For four of these, subjects were reinforced with food in the same manner as that normally during food-deprived training sessions. For the remaining four sessions, water reinforcement was available for responses which were normally reinforced during water-deprived training sessions. All correct responses were reinforced, regardless of whether they occurred in the presence of redundant or conflicting stimuli. Sessions preceded by both food and water deprivation will be referred to as test sessions. Since deprivation conditions were constant across these sessions, the effects exerted by reinforcement factors alone may be evaluated. All training and test sessions were 68 trials in length, and stimuli were chosen in the same manner as that used during Experiment I tests.

Table 1

\begin{tabular}{|c|c|c|c|c|}
\hline & \multicolumn{2}{|c|}{ Food-Light } & \multicolumn{2}{|c|}{ Water-Light } \\
\hline & Subject 1 & Subject 4 & Subject 2 & Subject 3 \\
\hline \multicolumn{5}{|c|}{$\begin{array}{l}\text { (a) Proportion of Choices Consistent With Control } \\
\text { by Light on Conflict Test Trials }\end{array}$} \\
\hline $\begin{array}{l}\text { Food } \\
\text { Water } \\
x^{2}\end{array}$ & $\begin{array}{c}.906 \\
.430 \\
21.76^{* * *}\end{array}$ & $\begin{array}{c}.836 \\
.516 \\
9.72^{* * *}\end{array}$ & $\begin{array}{r}.547 \\
.781 \\
5.29^{*}\end{array}$ & $\begin{array}{c}.578 \\
.898 \\
8.98^{* *}\end{array}$ \\
\hline \multicolumn{5}{|c|}{ (b) Proportion of Correct } \\
\hline $\begin{array}{l}\text { Food } \\
\text { Water } \\
x^{2}\end{array}$ & $\begin{array}{l}.984 \\
.961 \\
.036\end{array}$ & $\begin{array}{l}.953 \\
.945 \\
.004\end{array}$ & $\begin{array}{l}.977 \\
.961 \\
.016\end{array}$ & $\begin{array}{l}.945 \\
.945 \\
.0\end{array}$ \\
\hline
\end{tabular}

$* p<.05$

$* * p<.01$

$* * * p<.001$

\section{Results}

Figure 1 shows the percentage of choices consistent with control by light in the presence of conflicting compounds for each subject under the two training and testing conditions. Test sessions are represented by the broken lines, training sessions by the solid lines. The points on these solid functions represent performance on the two training sessions immediately preceding and following a test session using the same reinforcer. Thus, any point on a broken line was obtained during the interval between the recording of the two solid-line points immediately to its left and right.

Test sessions were first presented to Subjects 1, 2, and 3 following approximately 25 training sessions, whereas Subject 4 was run on over 60 sessions before testing was begun. Comparison of the training-session data in Figure 1 shows all subjects to have improved in performance on the sound discrimination over that observed for test sessions in Experiment 1 for which control by sound was predicted. Comparisons were made of the data of Figure 1a with that of the two training sessions preceding the first test in Experiment II. Improvement in control by sound was reliable beyond the .01 level for Subjects 1,2 , and $3\left(\chi^{2}=13.45,8.82\right.$, and 8.36 for Subjects 1,2 , and 3 , respectively), and fell between the .05 and .10 levels for Subject $4\left(\chi^{2}=3.65\right)$.

The data of Experiment II were collapsed across sessions for purposes of statistical analysis. For all four subjects, the differences between functions obtained on food-and water-deprived days are highly reliable.

Differences in the proportion of light choices between test and training sessions using food reinforcement were not reliable for any of the four subjects (Subject 1, $\chi^{2}=.12 ;$ Subject 2, $\chi^{2}=1.71$; Subject $3, \chi^{2}=.86$; Subject $4, \chi^{2}=.002 ; \mathrm{p}>.10$ for all subjects, $\mathrm{df}=1$ ). Differences obtained between test and training sessions using water reinforcement, however, were reliable for all subjects except Subject 3, who stopped responding very early in the second and third water-reinforced test sessions (Subject 1, $\chi^{2}=63.99, p<.001$; Subject 2, $\chi^{2}=4.78, \quad \mathrm{p}<.05 ; \quad$ Subject $3, \quad \chi^{2}=2.13, \quad \mathrm{p}>.10$; Subject $\left.4, \chi^{2}=36.08, \mathrm{p}<.001 ; \mathrm{df}=1\right)$. It should be noted here that the data of unfinished water-reinforced test sessions were used only if more than half of the session was completed within $1 \frac{1 / 2}{h}$. These include the second test for Subject 4 and Tests 2, 3, and 4 for Subject 2. No food-reinforced test failed to meet the completion criterion for any subject.

Data obtained in the presence of redundant pairs during the same sessions are given in Figure 2. For no subject was the difference in accuracy of performance between test sessions reliable (Subject 1, $\chi^{2}=.39$; Subject 2, $\chi^{2}=.19 ;$ Subject $3, \chi^{2}=.12 ;$ Subject 4, $\chi^{2}=1.29, \mathrm{p}>.10$ for all subjects, $\mathrm{df}=1$ ). This was also true of differences between training sessions (Subject 1 , $\chi^{2}=.27 ; \quad$ Subject $2, \quad \chi^{2}=.02 ;$ Subject $3, \quad \chi^{2}=.10 ;$ Subject $4, \chi^{2}=1.0, p>.10$ for all subjects, $\mathrm{df}=1$ ), and 
SI

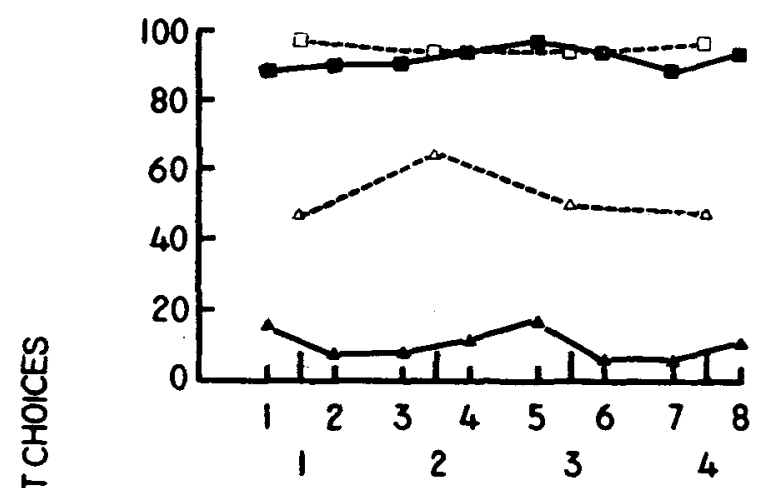

S2

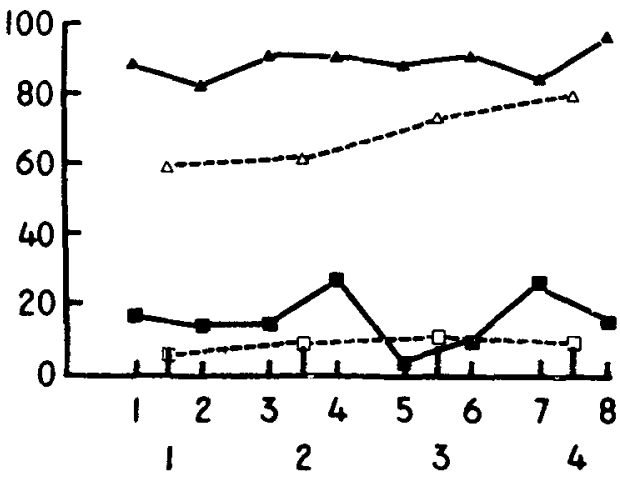

S3

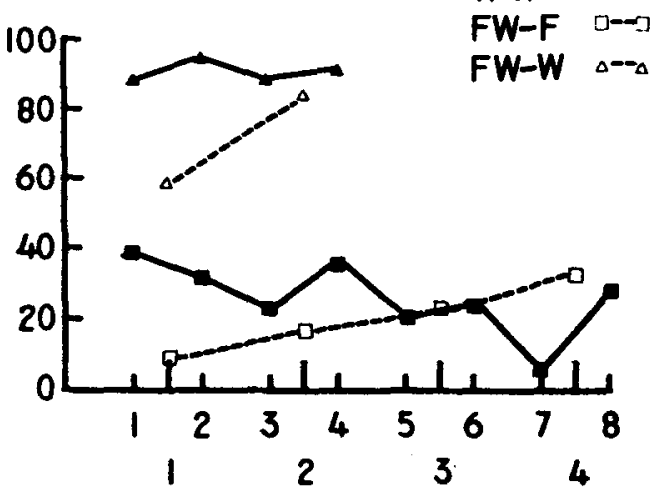

S4

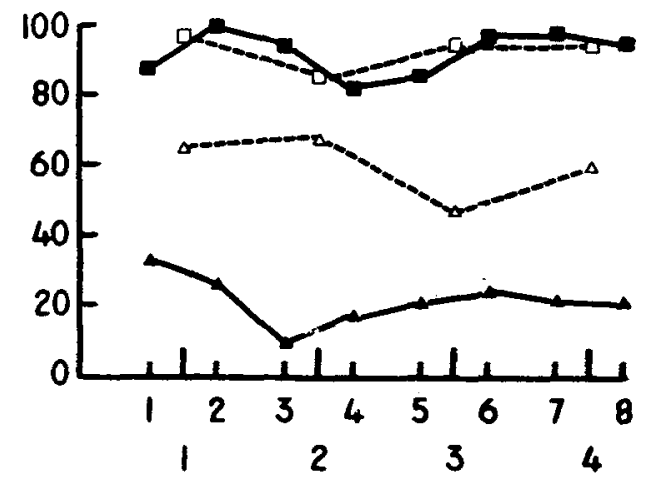

SESSIONS

Figure 1. Proportion of choices on conflict trials consistent with control by light for sessions using food deprivation and food reinforcement (F-F), water deprivation and water reinforcement $(W-W)$, food and water deprivation and food reinforcement (FW-F), and food and water deprivation and water reinforcement (FW-W).

training and test sessions using the same reinforcer (Subject $1, \chi^{2}=.12$ for water, .003 for food; Subject 2, $\chi^{2}=.01$ for water, .08 for food; Subject $3, \chi^{2}=.12$ for water, .06 for food; Subject $4, \chi^{2}=.01$ for water, .27 for food, $\mathrm{p}>.10$ for all comparisons, $\mathrm{df}=1$ ).

\section{DISCUSSION}

With extended training, performance during sound-relevant sessions tended to improve over that observed during Experiment I test sessions. Thus, preferences for responding on the basis of light were reduced. It should be pointed out, however, that even with this extra training, performance during training sessions for which sound was correlated with reinforcement was not as accurate as performance on sound-only sessions in Experiment I immediately following discontinuation of the correction procedure.

The results of Experiment II may provide us with some information as to the extent to which control by light vs. sound is determined by deprivation condition on the one hand or reinforcement on the other. For all subjects, reliable differences in choice behavior were observed between test sessions using different reinforcers. Since all test sessions were run under both food and water deprivation, these differences can be accounted for only by (1) the nature of the reinforcer used and/or (2) the contingencies in operation during the test.

The effects of deprivation condition can be evaluated by comparing test and training sessions using the same reinforcer. Since both the nature of the reinforcer and the reinforcement contingencies are held constant across these sessions, any differences in choice behavior must be due to deprivation condition. The data in Figure 1 shows that the effects of deprivation are not symmetrical. For no subject is the difference observed between training and test sessions using food statistically significant. Reliable differences are observed, however, for three subjects when the data obtained from sessions preceded only by water deprivation are compared with those of test sessions using water reinforcement. The behavior of Subjects 1,2, and 4 on conflict trials during water-reinforced test sessions cannot be attributed to a 
tendency to respond randomly during these sessions since this would imply that poor stimulus control should also be found in the presence of redundant compounds. Figure 2 shows that this is not the case. For all subjects, performance in the presence of these stimuli was highly accurate under all conditions, with no reliable differences attributable to either reinforcement or deprivation factors. This suggests that choice behavior was always under stimulus control and that changes in reinforcement and deprivation served only to determine the particular form which that control takes.

\section{EXPERIMENT III}

One possible explanation for the asymmetrical effects of deprivation condition is that the internal state resulting from deprivation of both food and water is more similar to that resulting from food deprivation alone than water deprivation alone. If this were true, then subjects should be more likely to eat than drink

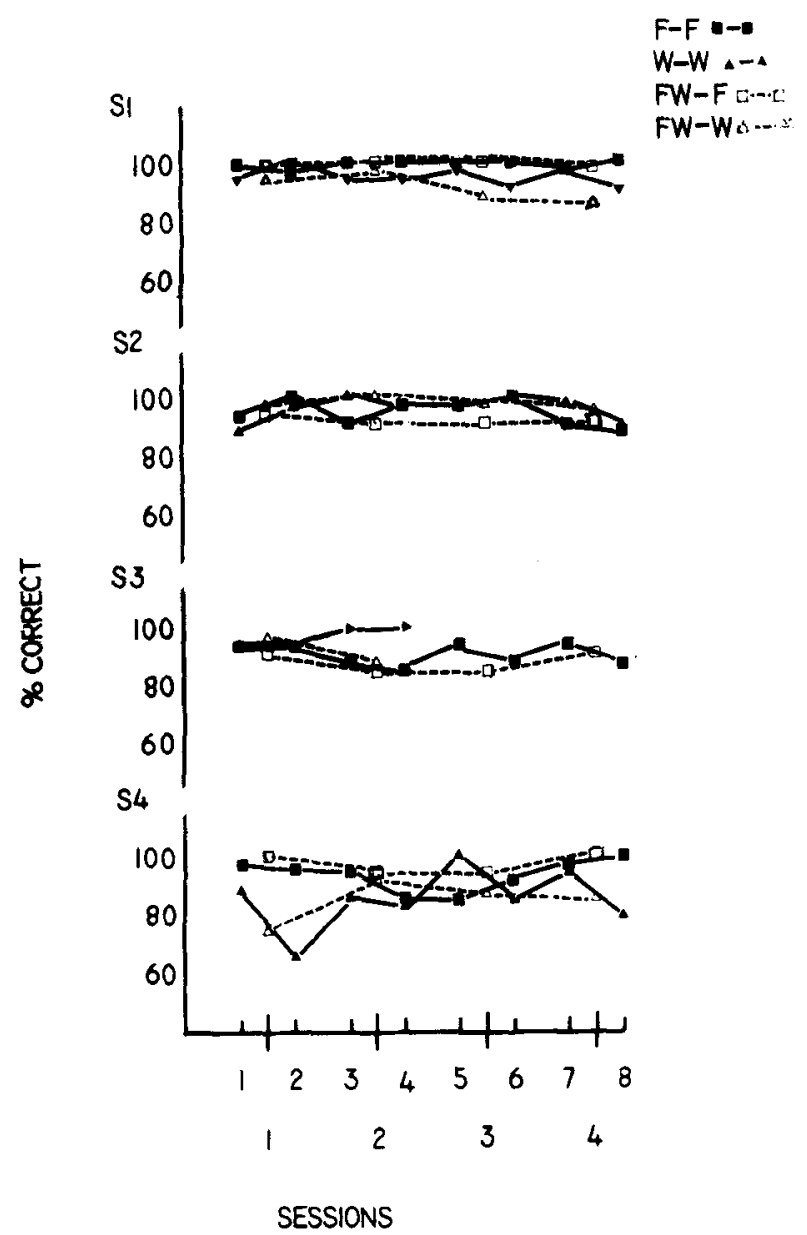

Figure 2. Proportion of correct choices on redundant trials for sessions using food deprivation and food reinforcement (F-F), water deprivation and water reinforcement $(W-W)$, food and water deprivation and food reinforcement (FW-F), and food and water deprivation and water reinforcement (FW-W).
Table 2

Quantities of Food and Water Consumed

\begin{tabular}{|c|c|c|c|c|c|}
\hline & \multirow{2}{*}{$\begin{array}{l}\text { Depri- } \\
\text { vation }\end{array}$} & \multicolumn{4}{|c|}{ Subject } \\
\hline & & 1 & 2 & 3 & 4 \\
\hline \multirow{3}{*}{$\begin{array}{l}\text { Food } \\
\text { Consumed } \\
(g)\end{array}$} & \multirow{3}{*}{$\begin{array}{l}\text { Food } \\
\text { Food \& } \\
\text { Water } \\
t\end{array}$} & 3.78 & 4.06 & 3.26 & 2.83 \\
\hline & & 3.06 & 3.89 & 3.14 & 2.71 \\
\hline & & 1.24 & .81 & 1.20 & .81 \\
\hline \multirow{3}{*}{$\begin{array}{l}\text { Water } \\
\text { Consumed } \\
\text { (ml) }\end{array}$} & \multirow{3}{*}{$\begin{array}{l}\text { Wates } \\
\text { Food \& } \\
\text { Water } \\
t\end{array}$} & 6.48 & 14.52 & 11.89 & 10.67 \\
\hline & & 3.71 & 4.07 & 1.36 & 4.29 \\
\hline & & $4.23^{*}$ & $27.69^{*}$ & $15.41^{*}$ & $19.06^{*}$ \\
\hline
\end{tabular}

$*_{p}<.001$

following deprivation of both food and water. The third study was designed to test this hypothesis.

\section{Method}

Subjects. The same four rats that were used in Experiments I and II.

Apparatus. A vacant living cage on the same rack used for housing the subjects served as a test chamber. The cage measured $17.8 \mathrm{~cm}$ wide $\times 17.8 \mathrm{~cm}$ high $\times 24.1 \mathrm{~cm}$ deep and was made of heavy wire mesh. The cage could be fitted with either a $100-\mathrm{ml}$ graduated drinking bottle or a metal foodcup of $6.4 \mathrm{~cm}$ diam, screwed to the floor.

Procedure. For a period of 9 weeks, subjects were exposed to the same schedule of alternating food and water deprivation that was used during Experiment 1I. Experimental sessions, however, were replaced with 5 -min periods of free access to either food or water. On days preceded by food deprivation, approximately $10 \mathrm{~g}$ of Noyes pellets were placed in the foodcup inside the test chamber. The water bottle was not fixed to the cage during these sessions. On days preceded by water deprivation, free access to tap water was given. For these sessions, the foodcup was removed from the test cage. Quantities of food and water consumed during these 5 -min test intervals were all recorded. Subjects were then returned to their home cages for a period of $2 \mathrm{~h}$ without food or water. Free access to both food and water was then given for the next hour, at the end of which a. new deprivation period began.

On 14 of the days during this 9-week period, each subject was deprived of both food and water. Food consumption was measured on half of these days, whereas water consumption was measured on the remaining days. Each of these consumption tests was conducted in exactly the same manner as those following food or water deprivation alone.

\section{Results and Discussion}

Table 2 shows the amount of food and water consumed by each subject following each type of deprivation period. In no case was the reduction in food consumption following both food and water deprivation reliably lower than that following food deprivation alone. Water intake, on the other hand, decreased significantly for all subjects when deprivation condition was shifted from water alone to food and water. This finding is consistent with the notion that the internal state resulting from food and water deprivation is similar to that arising from food deprivation alone but not to that arising from water deprivation alone. Similar 
findings have been reported by Heron (1949) and Manning (1956).

\section{GENERAL DISCUSSION}

\section{Critical Variables}

In the present study, several factors have been shown capable of determining which of two stimulus dimensions controls choice behavior. The major finding is that one of these is the cues produced by subjecting an animal to various conditions of food and water deprivation. It must be emphasized, however, that the precise nature of these cues cannot be specified on the basis of the data reported here; while food and water deprivation may produce qualitatively different drive stimuli (Hull, 1933), they may also alter the incentive values (cf. Bolles, 1967) of food and water as reinforcers. It is impossible to distinguish between these two alternatives on the basis of the present results.

A second factor determining stimulus control was found to be reinforcement. This was demonstrated in Experiment II where it was shown that the availability of food resulted in more choices consistent with the dimension associated with food than the availability of water, deprivation condition being held constant. In Experiment II, the cue value of reinforcement may lie either in the nature of the reinforcer itself or in the contingencies of reinforcement. Although it is not possible to separate these factors on the basis of work presented here, it has been reported previously that reinforcer factors alone can facilitate performance on a discrimination task (Hull, 1933).

The third determiner of stimulus control in the present study is that of saliency. Recall that the results of testing in Experiment I revealed control by light when the deprivation condition and reinforcer were both associated with light. When conditions associated with sound were in effect, however, only about half of the choice responses on conflict trials were consistent with control by sound. Thus, there appears to be a tendency to respond on the basis of light, regardless of its relevance to deprivation and/or reinforcement.

Saliency effects in animal subjects have been reported in the classical (Pavlov, 1927), CER (Kamin, 1968), free operant (Reyonolds, 1961) and avoidance (Thompson \& Van Hoesen, 1967) paradigms. In these studies, the presence of one of the components of a stimulus complex prevents a second from acquiring control over responding. In the present study, however, subjects received extensive training along both the light and sound dimensions and were performing both of these discriminations at nearly $100 \%$ accuracy before the correction procedure was discontinued. The poor control over choice behavior exercised by sound in Experiment $I$ tests cannot, therefore, be attributed to a failure of sound to have acquired control over discriminative responding, but rather to a preference for making choices on the basis of light.

\section{Theoretical Considerations}

Given that some of the variables critical in determining stimulus control have been established, we may now consider the question of fitting them into a theoretical framework. The problem of accounting for behavior which is under the control of cues along only one out of several available dimensions has been of much recent interest (cf. Sutherland \& Mackintosh, 1971). One approach to this problem has been to invoke an attentional mechanism; a subject is said to attend to a dimension if variations in stimuli along that dimension produce changes in behavior. Demonstrations of stimulus saliency cited above ("overshadowing") and the effects of various pretraining procedures ("blocking") are often taken as evidence for this process, and it is tempting to interpret the present findings in this light as well. Thus, deprivation might be seen as controlling the subjects' tendency to attend to light vs. sound.

Some of the problems of attentional interpretations have been pointed out by Chase and Heinemann (1972), who have shown that in redundant-cue procedures, control by the "unattended" dimension is not absent when sufficiently sensitive measurement procedures are used. Their data are supported by Zuckerman (1973). Consideration of the model which fits the data of both of these studies points to the need for specifying precisely what is meant by the term selective attention. Thus, it was found that the decision to actually respond on the basis of one or the other element of a stimulus compound is not made until both elements are examined (Zuckerman, 1973); both elements are "atended to" in the sense of being noticed, but only one eventually controls a given choice response.

The issue is raised at this time to point to the difficulties in interpreting results of the type reported here within an attentional framework. The factors of deprivation, reinforcement, and saliency have all been shown to affect the tendency to respond on the basis of light or sound. While this may reflect the operation of a simple attentional strategy (e.g., if food deprived, then attend to light), more sensitive measurement procedures using a wider variety of stimuli along each dimension may reveal that a far more complex response rule is actually being followed. The present data do, however, support the more general hypothesis that internal cues can play an associative role in multidimensional discrimination learning.

\section{REFERENCES}

Baker, R. A. Establishment of a non-positional drive discrimination, Joumal of Comparative and Physiological Psy chology, 1950, 43, 409-415.

Bliss, D. K.. Sledjeskí, M., Leiman, A. L. State dependent choice behavior in the rhesis monkey. Neuropsycholotin. $1971,9,51-59$.

Bolles, R. C. Theory of motivation. New York: Herper and Row, 1967

Chase, S., \& Heinemann, E. G. Choices based on redundant 
information: An analysis of two-dimensional stimulus control. Journal of Experimental Psy chology,1972,92,161-175.

Heinemann, E. G.. Chase, S., \& Mandell, c. Discriminative control of "attention." Science, $1968,160,553-554$.

Heron, W. T. Internal stimuli and learning. Journal of Comparative and Physiological Psychology, 1949, 42, 486-492.

Hull, C. L. Differential habituation to internal stimuli in the albino rat. Journal of Comparative Psychology, 1933, 16, 255-273.

Kamin, L. J. "Attention-like" processes in classical conditioning, in M. R. Jones (Ed.), Miami symposium on the prediction of behavior, aversive stimulation. Coral Gables, Florida: University of Miami Press, 1968. Pp. 9-33.

Leeper, $R$. The role of motivation in learning: A study of the phenomenon of differential motivation control of the utilization of habits. Journal of Genetic Psychology, 1935, 46, 3-40.

Manning, H. M. The effect of varying conditions of hunger and thirst on two responses learred to hunger or thirst alone. Joumal of Comparative and Physiological Psychology, 1956 , $49,249-253$.

Pavlov, I. P. Conditioned reflexes. Translated by G. V. Anrep. London: Oxford University Press, 1927.
Reynolds, G. S. Attention in the pigeon. Journal of the Experimental Analysis of Behavior, 1961, 4, 203-208.

Sutherland, N. S., \& Mackintosh, N. J. Mechanisms of animal discrimination learning. New York: Academic Press, 1971.

Thompson, C. P.. \& Van Hoesen, G. W. Compound conditioning: Ef fects of component intensity on acquisition and extinction. Journal of Comparative and Physiological Psychology, 1967. 64, 128-132.

Wickens, D. D., Hall, J., \& Reid, L. S. Associative and retroactive inhibition as a function of the drive-stimulus. Journal of Comparative and Physiological Psychology, 1949, 42, 398-403.

Yarczower, M Stimulus control during conditional discrimination. Journal of the Experimental Analysis of Behavior, 1971, 16,89-94.

Zuckerman, D. C. Steady-state responding based upon simple and compound stimuli. Journal of the Experimental Analysis of Behavior, 1973, 20, 209-218.

(Received for publication October 8,1974 ; revision received February 27,1975 .) 